\title{
Recent Sightings of Nanorana vicina (Dicroglossidae) from Murree, Pakistan
}

Muhammad Rais

Wildlife Management, PMAS Arid Agriculture University Rawalpindi, Pakistan (sahil@uaar.edu.pk)

Photographs by the author.

$\mathrm{P}$

akistan is predominantly an arid country with low anuran diversity in comparison with India and other Southeast Asian countries. Anurans in Pakistan are represented by 24 species belonging to cosmopolitan amphibian families, including Bufonidae, Microhylidae, Megophryidae, and Dicroglossidae. As many as six anuran species are thought to be endemic to Pakistan.

Our knowledge regarding the ecology, biology, and conservation status of anurans, including endemics, in
Pakistan is insufficient. Since the first report and description in 1872, the Muree Hills Frog (Nanorana vicina; Fig. 1) has not been collected from its type locality until recently when a team of herpetologists and postgraduate students from the Department of Wildlife Management, PMAS Arid Agriculture University Rawalpindi, Pakistan, was successful in finding two individuals.

The species is considered uncommon rather than rare or threatened. However, it has a high conservation value since

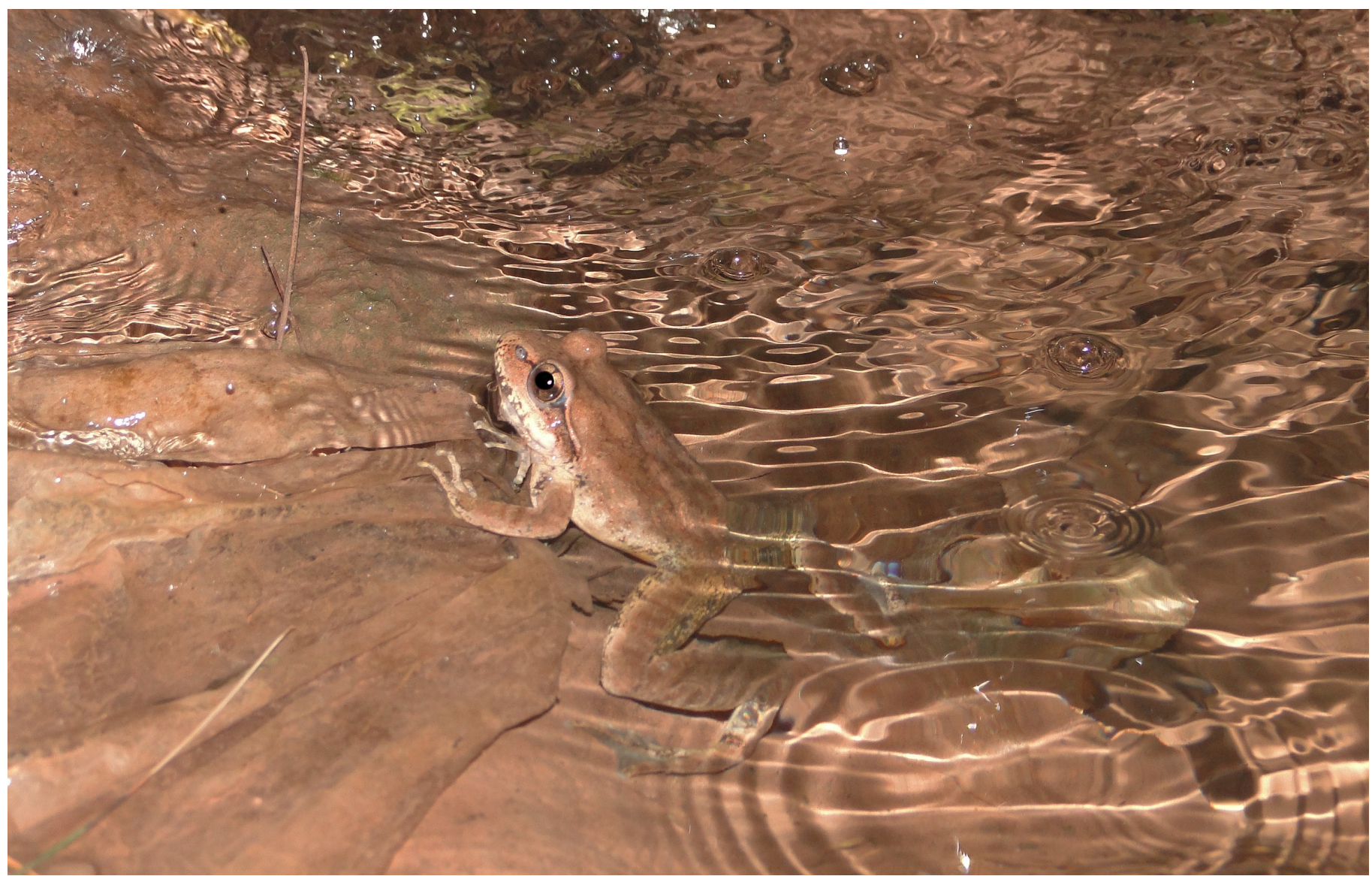

Fig. 1. Muree Hills Frog (Nanorana vicina) in its natural habitat. 


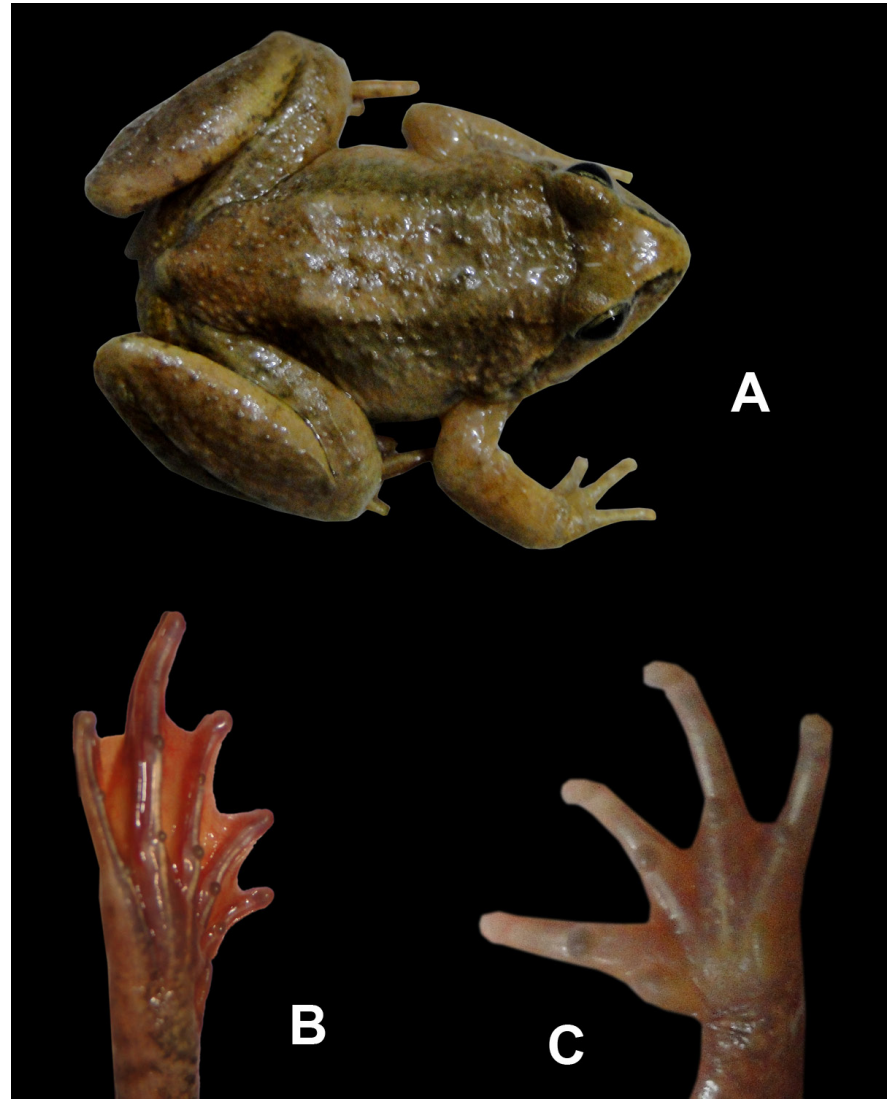

Fig. 2. Muree Hills Frog (Nanorana vicina). A. Female (dorsal view), B. foot, C. hand. Reproduced from the Journal of Animal and Plant Sciences Lahore 24:455-458 with permission from the editor.

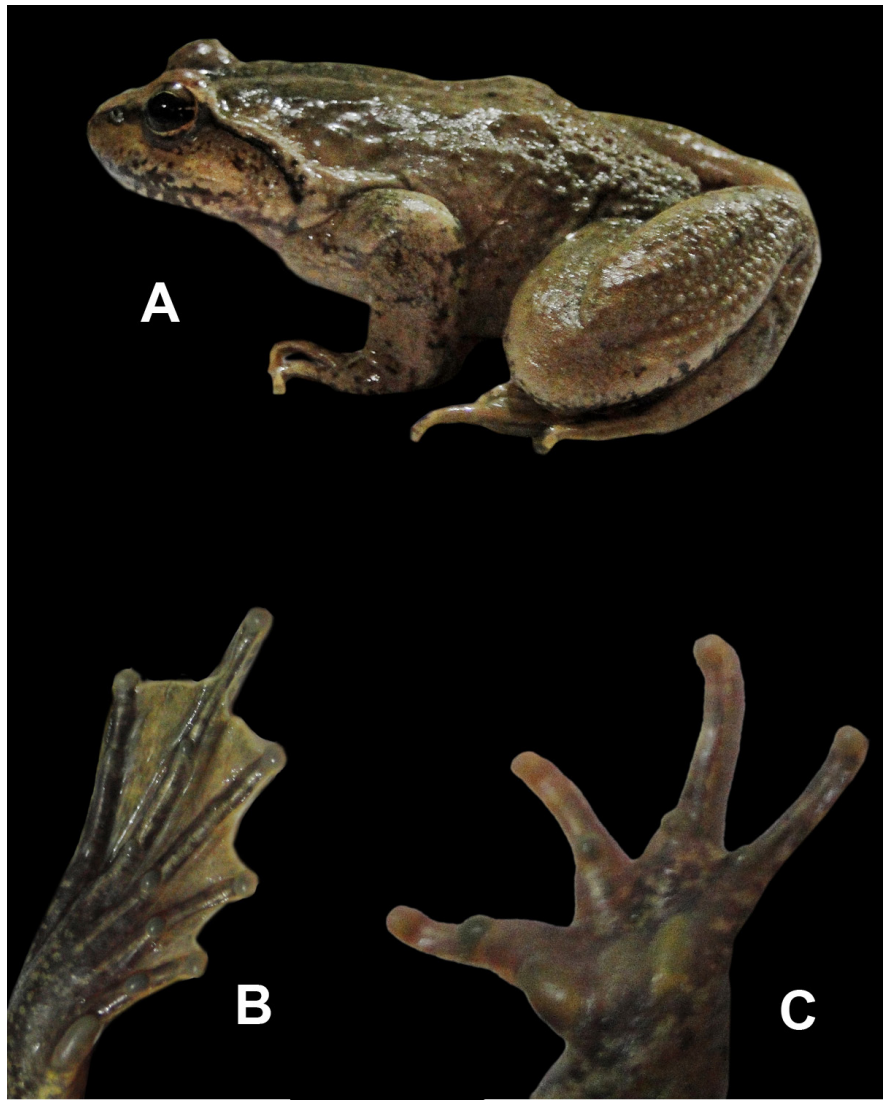

Fig. 3. Muree Hills Frog (Nanorana vicina). A. Male (lateral view), B. foot, C. hand. Reproduced from the Journal of Animal and Plant Sciences Lahore 24:455-458 with permission from the editor.

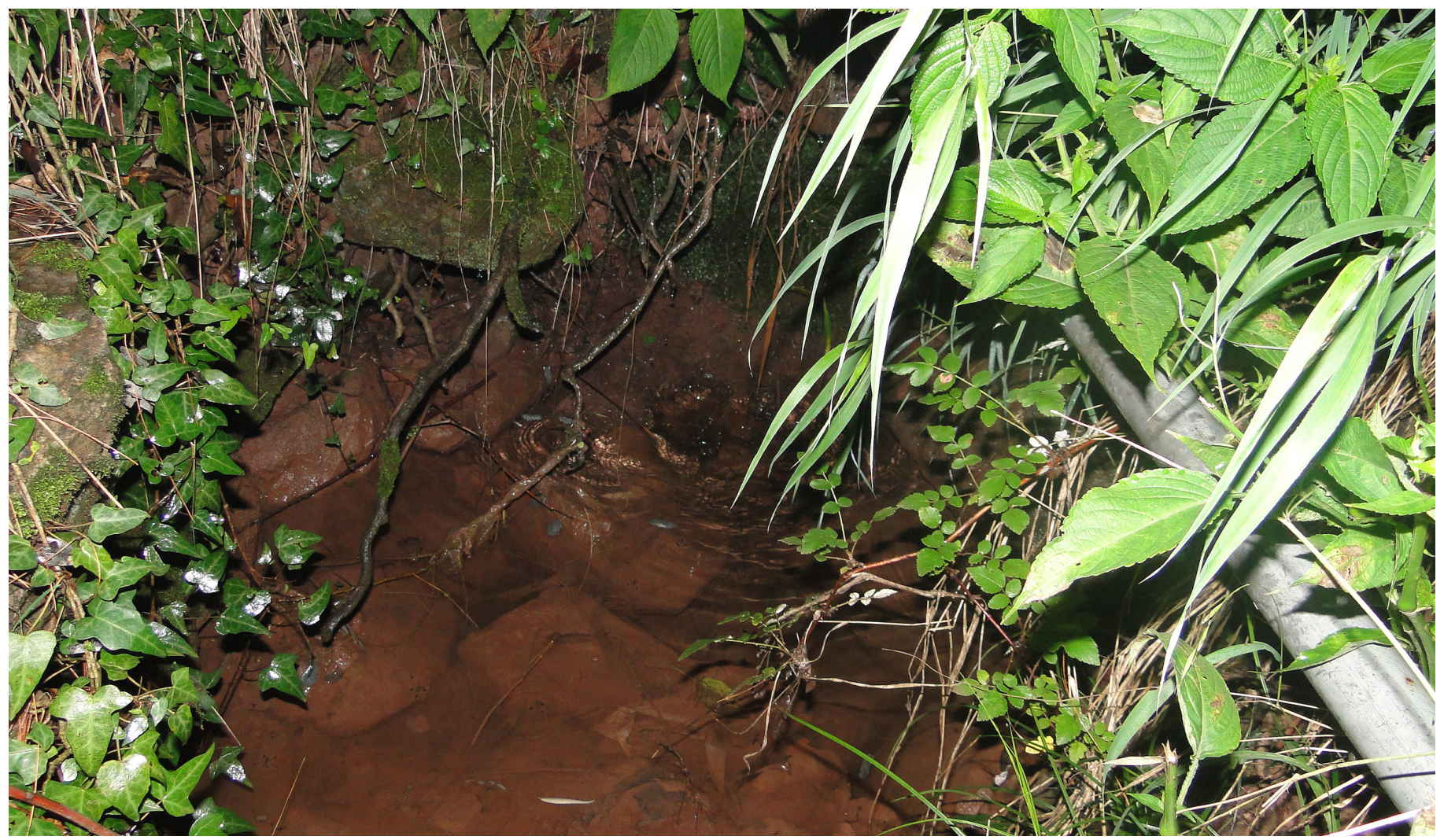

Fig. 4. Habitat of the Muree Hills Frog (Nanorana vicina) showing vegetation and a segment of a freshwater spring. 
it is endemic to Southeast Asian highlands. Further, it has high ED (Evolutionarily Distinct) and EDGE (Evolutionarily Distinct and Globally Endangered) scores of 2.64 and 12.96, respectively.

In a recent paper, Rais et al. (2014) provided a description of the two recently collected individuals along with photographs (Figs. 2-3) and data on morphometric measurements, habits, ecology, and conservation status. That paper concludes that the species inhabits clear lotic brooks (Fig. 4) at elevations as high as 2,500 m, including areas of Margalla Hills, Murre, Galiat, Ayoubia, and parts of Azad Jammu and Kashmir. The department is currently engaged in detailed studies on habitat, reproduction, DNA bar-coding, and radio-telemetric studies on movement patterns.

\section{Literature Cited}

Rais, M., S. Abbassi, T. Batool, M.J. Jilani, M.A. Assadi, H. Mubarak, and S. Baloch. 2014. A note on recapture of Nanorana vicina (Anura: Amphibia) from Murree, Pakistan. Journal of Animal and Plant Sciences Lahore. 24:455-458. 